\title{
Electrochemical Dechlorination of 1,2,4-Trichlorobenzene Using a Reticulated Vitreous Carbon Electrode
}

\author{
Ki-Jung Paeng, Chaevun Lim, Bo-Young Lee, ${ }^{\dagger}$ Noseung Mỵug ${ }^{\ddagger *}$ and Insook Rhee Paeng ${ }^{\dagger *}$ \\ Department of Chemistry, Yonsei Cniversin, Honju 220-710. Korea \\ 'Deparment of Chemistr, Seoul Homen's Chiversin; Seoul 139-774. Korea \\ ${ }^{\ddagger}$ Department of Applied Chemistrv. Konkuk Chiversitv Chungiu Campus. Chungilu, Chunghuk $380-701$, Korea \\ Received Mav 17, 2003
}

\begin{abstract}
Stepwise dechlorination of 1.2.4-trichlorobenzene was observed at a glassy carbon electrode in dimethylformamide containing $0.1 \mathrm{M}$ tetraethylammonium perchlorate. Especially. dechlorination to dichlorobenzene and further to monochlorobenzene or benzene was successfully denonstrated with a porous reticulated vitreous carbon electrode. Electrochemical dechlorination of polychlorobenzenes employing a flow: cell with a reticulated vitreous carbon working electrode is also described. Preliminary experiments with a flow cell showed that dechlorination of trichlorobenzene to dichlorobenzene was partially completed while dechlorination to benzene or monochlorobenzene was not successful, suggesting that a flow rate and electrolysis time should be further optimized for the complete electrolysis.
\end{abstract}

Key Words : Dechlorination. Flow electrolysis, Reticulated vitreous carbon electrode

\section{Introduction}

Polychlorinated aromatic compounds have been known as toxic pollutants due to their adverse effects on human health. persistence in the environment and accumulation in living organisms. ${ }^{1.2}$ Since removal of substituted chlorides can substantially reduce the toxic effects. dechlorination has been an extensively studied subject in the area of errironmental remediation. Although incineration or other oxidative procedures have been used for the complete destruction of cllorinated pollutants. more efficient and safer methods are still in demand since highly chlorinated aromatics have a strong resistance to oxidation (i.e. oxidative dechlorination) and furthermore oxidation can lead to the formation of toxic dioxins. ${ }^{3-5}$ In contrast. reduction of chlorinated pollutants does not yield dioxins.

Several reduction methods have been described. including electrolysis. treatment with molten metals. and heterogeneous catalysis. ${ }^{6-13}$ In particular. electrochemical methods that reduce chlorinated organic compounds to hydrocarbons are clean. easy to operate and cost efficient. They also exhibit high completeness for dechlorination.

Platinum. gold. palladium or lead oxide electrodes are frequently used as working electrode materials for the electrolytic reduction system. ${ }^{1+15}$ Although lead oxide is well known as an excellent electrode material for the electrochemical reduction of chlorinated benzenes. toxic lead metal ion might be leaching out under the harsh conditions such as very acidic wastes. Considering that flow electrolysis can result in high efficiencies and rapid conversions and are especially corvenient where large amount of solution are to be treated. development of a flow system

${ }^{*}$ Co-Corresponding authors. N. Myung (E-mail: myungta kku.ac.kr) I. R. Paeng (E-mail: irpaeng a'swu.ac.kr) employing a porous working electrode is highly required for the destnuction of ervironmentally important pollutants. ${ }^{16}$ In this report. preliminary results on the dechlorination of trichlorobenzene (TCB) employing a porous reticulated vitreous carbon (RVC) as a working electrode are described. Also. an attempt for the flow electrolysis of TCBs using a porous RVC is discussed.

\section{Experimental Section}

Reagents and materials. 1.2.4-trichlorobenzene (TCB) was purchased from Aldrich. 1.2-dichlorobenzene (1.2DCB). 1.3-dichlorobenzene (1.3-DCB). 1.4-dichlorobenzene (1.4-DCB) and monochlorobenzene (MCB) were purchased from Kanto. Dimethy lformamide (DMF. HPLC grade) from Millinckrodt was used as a solvent and tetraethylammonium perchlorate (TEAP) from Fluka was used as a supporting electrolyte. RVC working electrodes were obtained from Electrosynthesis. and a platinum counter electrode $(99.9 \%$. gauze) was obtained from Aldrich.

Electrochemical conditions. Electrochemistry of $\mathrm{TCB}$ was investigated with a standard three-electrode cell. The stationary non-flow. electrochemical cell consisted of a Pt mesh counter electrode. a glassy carbon working electrode and an $\mathrm{Ag} / \mathrm{AgCl} / 3 \mathrm{M} \mathrm{NaCl}$ reference electrode. All potentials are reported with respect to this reference electrode. The flow cell (Figure 1) was custom built with Teflon and consisted of a same three-electrode cell except the RVC working electrode $(10 \times 30 \mathrm{~mm})$. Cyclic voltammetry $(\mathrm{CV})$ measurements were carried out with an EG\&G PARC model 253 potentiostat/galvanostat. The flow cell was interconnected to a HPLC pump (Rainin. Dynamax Model SD-200) or a peristaltic pump (Gilson. Minipuls 3). Identification of electrolysis products was achieved with a UV/VIS detector (HP1050) which was connected to the flow cell. 


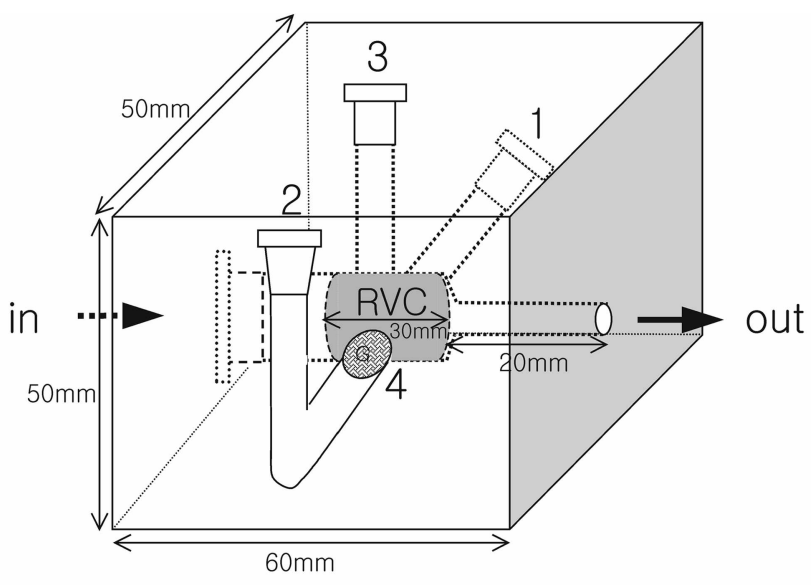

Figure 1. Schematic diagram of a flow cell: 1 = working electrode region. 2 = count electrode region. 3 = reference clectrode region. 4 glass trit. RVC, reticulated vitreous carbon electrode.

Chromatographic conditions. Chromatographic analyses were performed on a system which consisted of a pump (Perkin Elmer, Model LC-250), an injection valve (Rheodyne 7125 Injector) fitted with a $20 \mu \mathrm{L}$ loop, a C 18 column (Rainin, Microsorb-MV), a UV/Visible detector at $272 \mathrm{~nm}$ (Jasco, model UV-975), and a Hewlett Packard integrator (HP-3394A). The eluent consisted of water/acetonitrile $(70 / 30)$.

\section{Results and Discussion}

Instead of a lead dioxide electrode that is not environmentally benign, we tried a carbon electrode as a working electrode for the dechlorination. A cyclic voltammogram of $1,2,4-\mathrm{TCB}$ at the glassy carbon electrode in DMF containing 0.I M TEAP is shown in the Figure 2. Three consecutive reduction peaks, suggesting stepwise dechlorination of $1,2.4-\mathrm{TCB}$, at $-2.2 \mathrm{~V},-2.5 \mathrm{~V}$ and at $-2.7 \mathrm{~V}$ are well matched with the literature values. ${ }^{17}$ This $\mathrm{CV}$ implied that complete dechlorination could be obtained by the controlled potential

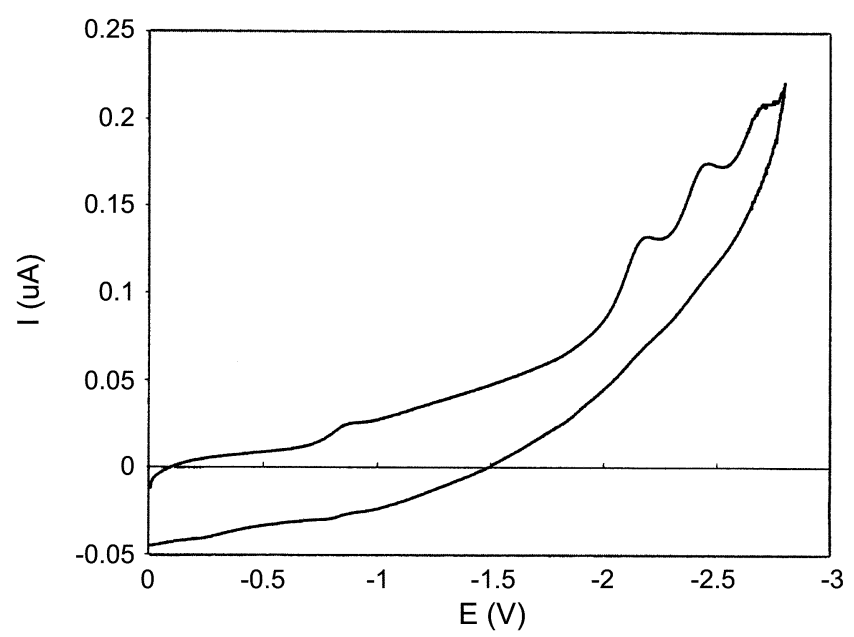

Figure 2, Cyclic Voltammogram tor l mM 1.2,4-TCB in DMF containing $0.1 \mathrm{M} \mathrm{TEAP}$ at a glassy carbon clcetrode $\left(0.14 \mathrm{~cm}^{2}\right)$. Scan rate: $100 \mathrm{mV} / \mathrm{s}$. electrolysis. Next, for the intention of developing a flow cell, we examined the RVC electrode in a stationary cell.

$\mathrm{RVC}$ is an open pore material with a honeycomb structure and combines the electrochemical properties of glassy carbon with hydrodynamic and structural advantages. Due to the physical structure, chemical and electrochemical characteristics, RVC electrodes are extremely attractive for various electrochemical purposes such as preparative electrolysis, removal of metal ion contaminants and flow analyses. ${ }^{18}$ Especially, high surface area results in electrolysis yields up to $100 \%$ and high void volume and sufficient porosity provide low resistant to flow even after deposition of thick metal films. Like solid glassy carbon. RVC electrodes are inert to a wide range of reactive chemicals and have a wide potential range. In addition, they may easily be machined into various shapes and mounted in various cell configurations. Here, we used a RVC electrode with the porosity of 100 ppi (pores per inch)

During the electrolysis of 1,2,4-TCB using a RVC electrode at $-2.7 \mathrm{~V}$, small amount of solutions were sampled and analyzed with the HPLC. Products of electrolysis were identified by the comparison of a chromatogram obtained from the electrolysis with the one obtained using standard chlorobenzene samples.

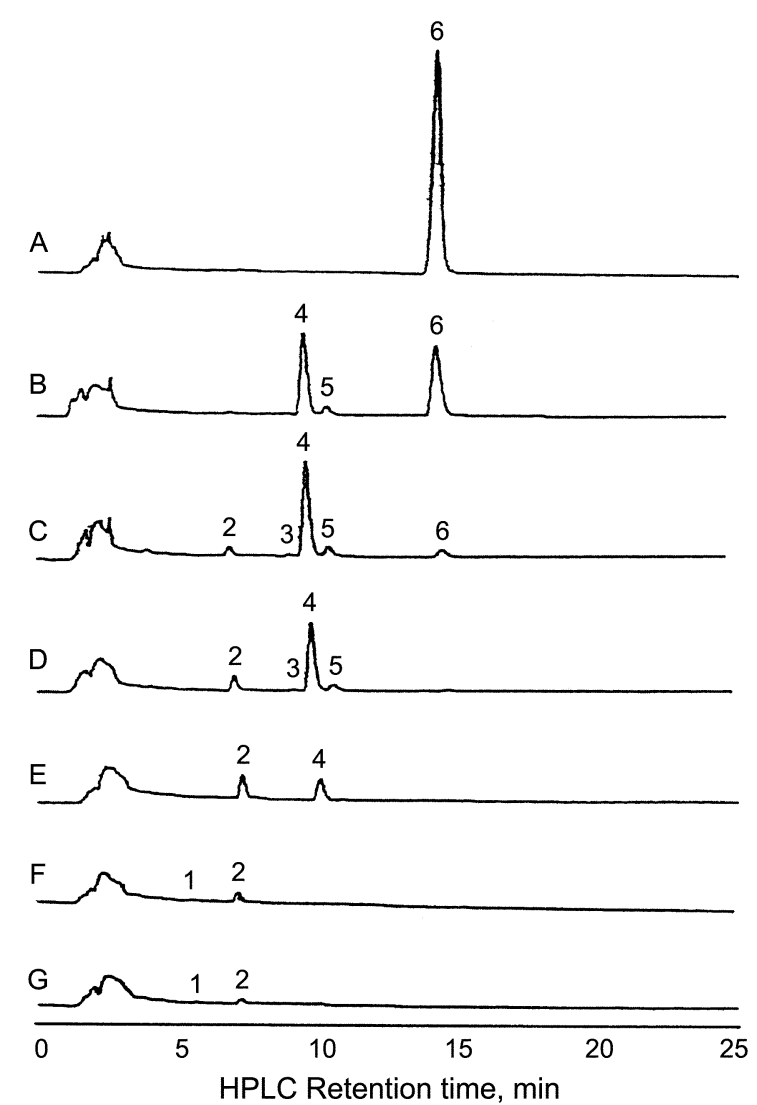

Figure 3. Chromatograms obtained during the elcetrolytic reduction ol $\mathrm{TCB}$ in D.MF containing $0.1 \mathrm{M} \mathrm{TFAP}$ at $-2.7 \mathrm{~V}$ with a RVC electrode. Reaction time: $A=0$ min. $B=5$ min. $C=15$ inin. $D=30$ min. $E=60$ min. $F=120$ min. $(j=180 \mathrm{~min}$. Peak number: $l$ $=$ Benzenc. $2=$ MCB. 3 = 1.2-DCB. $4=1.4$-DCB. $5=1.3-$ DC.B. 6 $=1,2,4-1 \mathrm{Cl} 3$. 


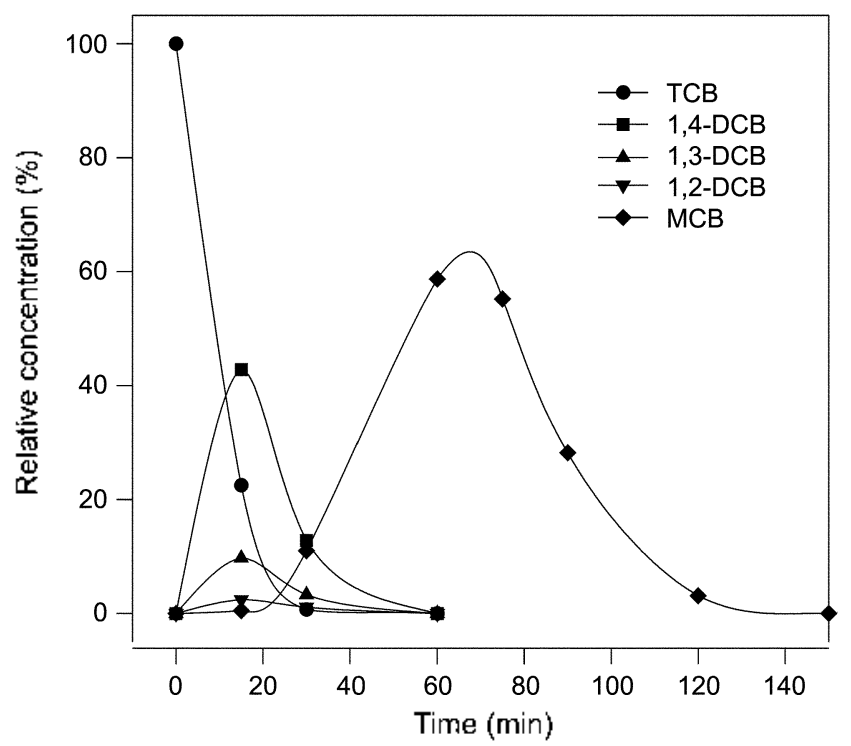

Figure 4. Concentration changes of chlorinated benzenes during the electrolysis of I $\mathrm{mM}$ 1.2.4-1 $1 \mathrm{Cl} 3$ in $\mathrm{DMM}$ containing $0.1 \mathrm{M}$ TEAP at a RVC electrode $\left(9.14 \mathrm{~cm}^{2}\right)$ held at $-2.7 \mathrm{~V}$.

Figure 3 shows the chromatograms obtained from the product of electrolysis. As shown in the Figure, the peak from the 1,2.4-TC.B decreased as a function of electrolysis time and finally it disappeared in the chromatogram obtained at $30 \mathrm{~min}$. In other words, dechlorination of 1,2,4-TCB to DCB (mainly 1.4-DCB) was almost completed after $30 \mathrm{~min}$. of electrolysis. Besides 1,4-DCB, other DC.Bs such as 1,2and 1,3-DCB were also detected (see below) in the chromatograms. All the peaks from the DCBs disappeared after $60 \mathrm{~min}$. and MCB peaks showed a similar behavior of increase and decrease. Finally, no more peaks were shown in the chromatogram after 3 hours of electrolysis, implying the complete dechlorination of 1,2,4-TCB. From this experiment. the $R^{2}{ }^{2}$ electrode was found be well suited for the dechlorination of TCBs and further for the flow electrolysis. Figure 4 summarized results, showing the relative concentration changes as a function of electrolysis time. It is noteworthy that all chromatograms show very weak signals from benzene mainly due to the substantially lower absorbance of benzene than other chlorinated benzenes at the selected wavelength $(272 \mathrm{~nm})$.

Based on the above results, dechlorination of I,2,4-TCB to DCB was proposed to follow the mechanism in the Scheme 1. The radical anion is generated with the addition of one electron to 1,2,4-TCB and then dechlorination initiates at that site. Carbon anion is generated as the second electron is added and the dechlorination reaction is completed after addition of hydrogen to that position. In general, $O-C l$ is removed faster than $p$ - or $m-\mathrm{Cl}$ and thus $1.4-\mathrm{DC} \mathrm{B}$ is the major product after the first stage of dechlorination of $1,2,4$ TCB. ${ }^{19}$ Unfortunately, an initial attempt for the complete dechlorination of TCB using a flow cell was unsuccessful possibly due to the huge electrolysis time for dechlorination even at the various flow rates. Therefore, we tried to electrolyze the TCBs to MCBs using a flow cell since conversion of

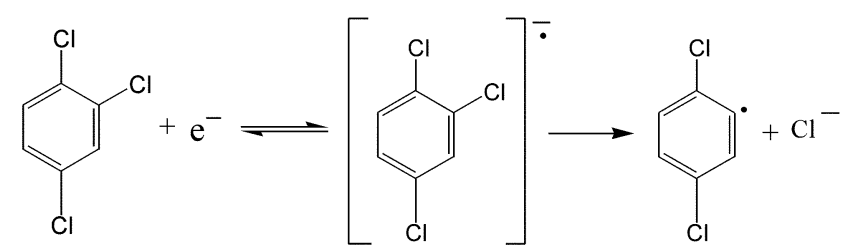

$1,2,4-\mathrm{TCB}$

(A)

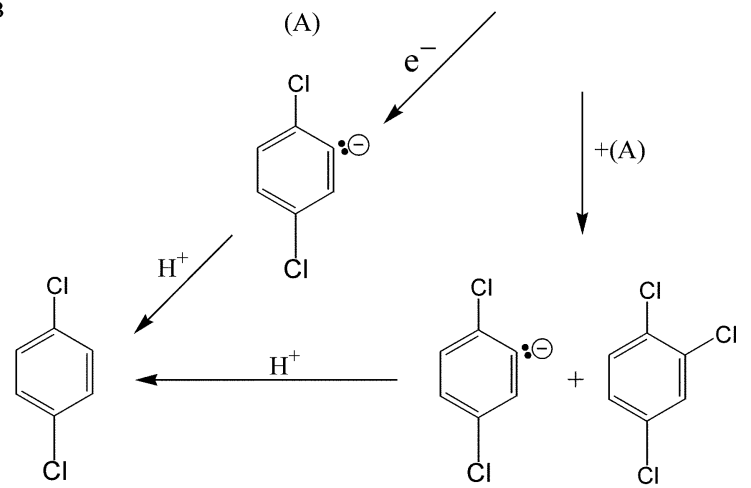

1,4-DCB(major product)

Scheme 1

TCB to DCB was found much faster. Electrolysis of $1,2,4-$ TCB in DMF containing 0.1 M TEAP to DCB was performed with the flow cell depicted in Figure I. Figure 5 shows the chtomatograms obtained from the electrolysis product sampled from the flow cell at the different time. Initially, only TCB was detected from the effluent and dechlorination of TCB to DCB was detected after 60 minutes. Dechlorination to 1,3and 1,4-DC'Bs was also clearly observed. In spite of the

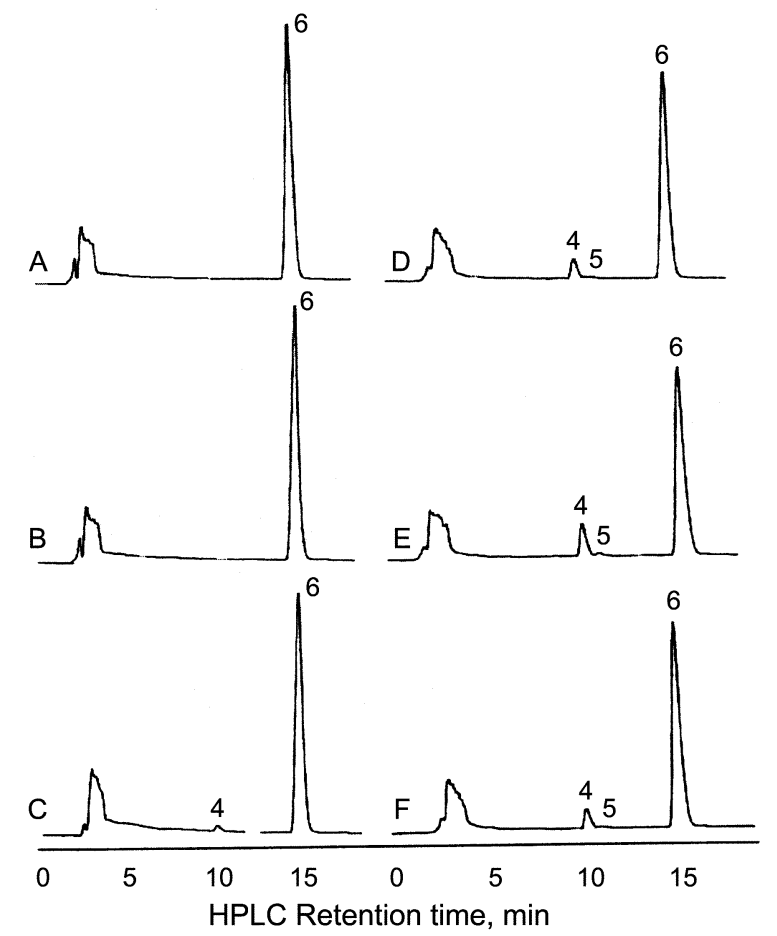

Figure 5. Chromatograms obtained during the flow electrolytic reduction of TC B in DMF containing $0.1 \mathrm{M} \mathrm{TEAP}$ at $-2.2 \mathrm{~V}$ with a RVC electrode. Flow rate: $0.1 \mathrm{ml} / / \mathrm{min}$. Reaction time: $A=0$ min. $\mathrm{B}=30 \mathrm{~min}, \mathrm{C}=60 \mathrm{~min}, \mathrm{I}=70 \mathrm{~min}, \mathrm{~V}=80 \mathrm{~min}, \mathrm{~V}=90 \mathrm{~min}$. Peak: $4=1.4-$ DC.B. $5=1.3-$ DC.B. $6=1.2 .4-$ TCB. 
extended electrolysis time. no more dechlorination was achieved under the various experimental conditions (e.g. different flow rates). In other words. the chromatograms showed no substantial changes in peak heights of TCB and DCB as a function of time. It may be attributed to the fact that contact time or electrolysis time was not enough under this condition based on the cell volume and flow rate. Nevertheless. preliminary experiments with a stopped-flow: experiment showed substantially improved electrolysis efficiency. In this experiment. the flow cell was filled with electrolyte containing TCB and stopped for electrolysis at a given potential. Then a flow of solution resumed and sampled solutions were analyzed with a chromatographic method. This method increased reaction time and therefore sensitivity without dilution of sample zone by dispersion. Although the flow electrolysis of TCB under the present experimental set up was not satisfactory. increase of contact time by the longer RVC electrode or repeated electrolysis may result in better performance and complete dechlorination.

In summary. dechlorination of TCB was demonstrated ussing a porous RVC working electrode. For the non-flow conditions dechlorination of 1.2.4-TCB to DCB (mainly 1.4-DCB) and further to MCB and benzene was successfully achieved and it was found that RVC electrode was found be well suited for the easy and fast dechlorination of TCBs. However. flow experiments showed incomplete electrolysis due to the several reasons such as insufficient electrolysis time. flow rate and electrode surface area. Nevertheless. the possibility for the flow electrolysis of polychlorinated benzenes was demonstrated.

Acknowledgement. This work was supported by Korea Science and Engineering Foundation (2000-1-12400-00l-5).

\section{References}

1. PCBs. Human and Enimoment Hazards; D'L tri, F. M.; Kamrin. M. A.. Eds.: Butterwoth Publishers: Boston. U. S. A.. 1983.

2. Safe. S. Crit Rev Toxicol 1984. 13. 319

3. Liu. Y.: Schwartz. T.: Cavallaro. C. L. Eninon. Sei. Technol 1995. 29.836 .

4. PCBS and the Emiromment: Waid. J. S.. Ed.: CRC Press: Boca Raton. U. S. A.. 1986.

5. Evans. D. H.: Pirbazari. M.: Benson. S. W.: Tsotsis. T. T.: Devinny. T. S. J. Hazard. Mater. 1991. 27. 253.

6. (a) Shultz. C. G. Chem. Abstr 1986. 105. 48445 n. (b) Lalancette. J. M.: Belanger. G. Camada Patent 1,2+7,139. 1988

7. Loiselle, S.: Branca M: Mulas, G.; Coceo. G. Entron. Sci. Techol. $1997,31.261$.

8. (a) Roth, J. A.: Dakoji. S. R.: Hughes, R. C.: Carmody: R. E. Environ. Sci. Techol 1994. 28. 80 (b) Dentnis. W. H.. Tr.: Chang. Y. H.: Cooper. W. I. Bull. Entron. Contan. Toxicol. 1979. 22. 750 .

9. Gantzer. C. J.: Wackett. L. P. Eminon. Sci. Technol 1991. 25, 715.

10. Sorokin, A.: Meunier. B. Chem Commun. 1994, 15. 1799.

11. Zhang. S.: Rusling. J. F. Environ. Sci. Techol. 1993, 27.1375.

12. Ross. N. C.: Spackman1. R. A.: Hitchnnan. M. L.: White. P. C. $d$. Appl. Electrochen 1997.27.51.

13. Cheng. I. F.: Fernando. Q.: Korte. N. Eninon. Sci. Techmol. 1997. 31. 1074 .

14. Kim. S.: Yun. S.-E.; Kang, C. Bull. Korean Chem. Soc, 2001, 22. 1192.

15. Myung. N. Bull. Kowan Chem. Soc. 2001. 22. 994.

16. Bard. A. J.: Faulkner. L. R. Electrochenical Methods: Fundanentals and.Applications. 2nd ed.: Wiley Press: New York. U. S. A. 2001 : $\mathrm{p}+\mathrm{tl}$

17. Qui. A.. Ph. D. Dissemtation. Texas A\&M University: College Station, Texas, 1992.

18. Wang. T. Electrochim. Acta 1981.26.1721.

19. Organic Electrochentism: An Introduction and a Guide. 3rd ed: Lund. H.: Baizer. M. M.. Eds.: Marcel Dekiker: New York. U. S. A., 1991: p 382

20. Skoog. D. A.: Holler, F. J.: Nieman, T. A. Principles of hastumtental Analysis, 5th ed.: Saunders College Publishing: 1998: p 838. 